\title{
Characteristics of Pre-Proceedings and Care Proceedings Cases in an English Local Authority, 2013-2017: An Exploratory Data Analysis
}

\author{
Chris Dyke (1) *,
}

\begin{abstract}
STACS Department, Goldsmith's College, 31 St James, London SE14 6AD, UK
*Correspondence to Chris Dyke, STACS Department, Goldsmith's College, 31 St James, London SE14 6AD, UK. Email: c.dyke@gold.ac.uk

${ }^{\dagger}$ The author has subsequently moved to the following address: Institute of Education, UCL, 18 Woburn Square, London WC1H 0NR, UK.
\end{abstract}

\begin{abstract}
Since reforms in 2014, care proceedings-where a local authority seeks to intervene legally to protect a child-have become shorter, with greater emphasis on 'front-loading' preventative and analytical work before, rather than during, proceedings. National findings on case outcomes are emerging, but in-depth local analyses are still rare. This exploratory data analysis of 937 children in 522 families in one London local authority sought to identify trends in the length, outcome and nature of preproceedings and proceedings cases, including outcomes six, twelve and twenty-four months after the end of these processes. Consistent with national-level findings on care proceedings, from 2013 to 2017 both the pre-proceedings and care proceedings processes became shorter, and more likely to end with the child at home. The data do not suggest that this increased 'decisiveness' leads to rushed decisions. Only 1.4 per cent of the children stepped-down from pre-proceedings, and 6.6 per cent of the children who remained at home after care proceedings came into care within two years of that decision. This research offers a model for similar analyses by practitioner researchers within their own local authorities.
\end{abstract}

Keywords: care proceedings, children act

Accepted: August 2019 


\section{Introduction}

Reforms to the public law outline (PLO) for child-care proceedings in England and Wales sought to address problems of case drift and poor preparation for court, focussing on shortening proceedings, diverting cases from court where possible, and conducting necessary assessments and interventions before rather than during a court case. The headline reform was a twenty-six-week limit on the length of proceedings (with exceptions), while judges also had to justify why any external expert should be instructed during proceedings.

When a local authority children's services department fears that a child is suffering, or at risk of suffering, significant harm through abuse or neglect under section 31 of the Children and Families Act 2014, they convene a legal planning meeting (LPM) to consider whether the section 31 threshold has been met. The outcome of this meeting may be:

- that the threshold is met and the local authority should apply to the court immediately for an order to keep the child safe;

- that the threshold is not met and the local authority continue working with the family (under a child protection or child in need plan); or

- that the threshold is met, but there is insufficient urgency to go to court immediately. Chapter 2 of the government's statutory guidance on the reforms (DfE, 2014) covers the resulting 'preproceedings' process. This process will end either with the local authority applying to court (having conducted any expert assessments or necessary interventions) or with the local authority 'stepping down' the case when the threshold for significant harm is no longer met.

While early research on the effects of the reforms has been cautiously positive, evidence of meaningful changes has come from two levels: indepth qualitative studies looking at social workers' views and experiences of the reforms; and findings at a national level.

This research involves a detailed case study in one local authority to identify whether local data reflect national trends-an exploratory data analysis of the changes in case outcomes over the years 2013-2017 as the new PLO has been implemented, identifying emerging trends to inform practice. Creating and analysing a dataset of all pre-proceedings and care proceedings during this period allow a more detailed examination of trends than the former, with more focus on an individual local authority than the latter. During the period 2013-2017, the local authority amended its procedures to incorporate the full requirements of 
the PLO. While they also created a consultant practitioner role to oversee this process, this appointment post-dates the period in question.

\section{Literature review}

This research asks:

1. what are the characteristics of cases in pre-proceedings and care proceedings in one local authority; and specifically

2. do any concerning trends emerge about case outcomes that require further investigation? Essentially, was the local authority 'missing anything'?

This literature review explores how other researchers have examined the link between procedural changes to public law, and outcomes for the children concerned. I identified literature through keyword searches of Google Scholar, Web of Science and university repositories, for terms, including 'PLO'; 'care proceedings outcomes'; 'child care proceedings' and 'child court proceedings England', initially restricting searches to 2015 onwards, but also reviewing the most commonly discussed earlier citations in recent research.

Decision-making for children at risk of harm can involve conflict between effectiveness and efficiency: between the need to ensure decisionmaking is thorough and best serves the child's welfare, and the need to make this decision in a timely fashion. A rushed decision that omits important features of a child's life may disadvantage them, but so does delaying that decision until a large portion of their childhood has passed. The reforms to the PLO, ultimately written into law in the Children and Families Act 2014, exemplifies this trade-off, with their focus on timeliness while still looking to preserve or improve the quality of decisions.

This echoes a wider debate within the profession about the role of formal regulations and guidance, particularly when these create tension between professional judgement and procedural requirements. There is well-established concern in the literature about the danger of managerial systems impairing, rather than assisting, good practice between social workers and service users: the 'audit culture' (Munro, 2004); the 'descriptive tyranny' of electronic records and processes (Peckover et al., 2007); or the use of a rigid technical framework to make a complex decision (Platt and Turney, 2013). Many fear the 'McDonaldisation' (Dustin, 2016) of social work, where professional judgements are outweighed by an emphasis on completing a task within a timeframe according to a protocol. 
The two most significant changes in the PLO were:

1. a greater emphasis on the pre-proceedings period, with a view to preventing cases coming to court where possible or, otherwise, making sure that cases reached the court with all assessments complete and with a clear basis for the court to make a ruling; and

2. a requirement that all care proceedings cases should be resolved within twenty-six weeks, unless exceptional circumstances required this time to be extended.

\section{Response to the pre-proceedings reforms}

The focus on the pre-proceedings phase has been welcomed, with some reservations: Broadhurst and Holt (2009) recognised that procedures will only have a limited effect on practice, while Dickens and Masson (2016) were concerned that the emphasis on pre-proceedings work might lead to social workers seeing their involvement as 'preparation for court' rather than helping to avoid that eventuality. Masson et al. (2017) found that since the PLO reforms, local authorities were taking less time to bring a matter before the court, and less likely to do so because of a crisis. From a practitioner perspective, Holt and Kelly (2015) found a mixture of professional concern about increased regulation, and recognition that the reforms placed more emphasis on effective partnership working with families, which social workers valued.

\section{Response to the court reforms}

A Research in Practice (2016) study that found 'strong support' for the reforms amongst the workforce, including the twenty-six-week deadline, while Beckett et al. (2016) found improved placement stability, improved decision-making and reduced delay after the final hearing in the pilot scheme. Beckett and Dickens (2018) used the twenty-six-week deadline as 'a rare example of a national target that works': their study of 180 cases before and after the reform found that outcomes and quality of decisions were not impaired by the increased timeliness of both proceedings and the pre-proceedings process. They commented on the flexibility of the deadline, and the level of consultation with the profession before introducing it, as possible contributing factors towards this positive picture. During her long-term study of care proceedings after the reforms, Masson (2018, unpublished data) found that proceedings were getting shorter, fewer experts were being called, and the courts were becoming less likely to make placement orders.

However, Masson (2014) worried that the renewed emphasis on assessing family members, after the $\operatorname{Re} B-S$ case restated existing law 
(requiring local authorities to assess all feasible options before recommending a care order or placement order), had amplified the time pressure of the twenty-six-week deadline. Likewise, Gupta and Lloyd-Jones (2016) argued that the intense complexity of family dynamics often involved in kinship care made it hard to implement both the expectations in $R e B-S$ case as well as the Children and Families Act 2014, which enshrine the twenty-six-week deadline into law.

Masson et al. (2018) found 22 per cent of cases stepped-down from court with a supervision order returned to court within two years, and (for another sample) 31 per cent returned to court within six years.

\section{The role of this research}

This study frequently references the provisional findings of Judith Masson and her colleagues, although their major study into the PLO reforms - the largest of its kind-is still ongoing at the time of writing in early 2019. This and other large studies focus on the national and regional picture, while this study aims to complement these larger projects with a focussed, micro-level exploration of the cases subject to legal planning in one local authority.

The study emerged from a collaboration between my university and a nearby local authority, who commissioned this research to explore how the shift to shorter, 'frontloaded' court work had affected outcomes in court cases: what kinds of cases went through care proceedings; whether they progressed to care proceedings or stepped-down; and how the outcomes of court proceedings have changed over the preceding three years. The local authority was also concerned about whether their decision-making was sufficiently thorough despite shorter proceedings, and whether different case characteristics were associated with different outcomes. Feedback from this analysis helped guide their ongoing review of pre-proceedings casework, and sparked further exploration of physical abuse cases. As Rutter and Fisher (2013) found, this model of 'co-production' between researchers and practitioners made the project itself easier to carry out and produced relevant findings for operational staff, making it easier for them to incorporate the findings into their case management.

\section{Methodology and sample}

Since the research questions are relatively open, an exploratory case study using quantitative methods is best suited to answering them. A large dataset gives more insight into trends within the local authority that an exploration of themes in a smaller sample-a quantitative 
approach allows findings that are more representative of practice within this local authority.

The local authority supplied comprehensive trackers with information on 937 children (in 522 families) involved in care proceedings and preproceedings between 2011 and 2017. I initially analysed the sample bychild, so that a 'case' refers to one child's case (rather than one family's case). This allows analysis of the sample by age and outcome-analysis by-family is complicated by the differing characteristics, case history and outcome for different children, in many cases. While details for different siblings obviously overlap, the court and local authority make decisions for each child, based on that child's circumstances. This sample included twelve children subject to LPMs in 2011, ninety in 2012, 195 in 2013, 161 in 2014, 199 in 2015, 134 in 2016 and forty-six in 2017. The figure for 2017 is incomplete, and the figures for 2011 almost certainly so. The leap from 2012 to 2013 suggests a gap in the data from 2012, but could also reflect the nationwide, sustained increase in care proceedings cases over the past decade, with most boroughs reporting increases of 15-20 per cent per year (Lord Chief Justice, 2017). The sample excluded any cases where the outcome of the LPM was for no further action (not even pre-proceedings) as these cases were not tracked. When analysing the situation six or twelve months after stepping-down or final hearing, the study excluded more recent cases. The sample therefore shrinks to 901 children for the six-month follow-up (due to thirty-six cases having been resolved for less than six months at the time of the research) and 753 children for the twelve-month follow-up (a further 148 having been resolved for between six and twelve months).

\section{Ethics statement}

The methodology and use of data were approved in advance by the university social work department and by the Head of Service who granted permission to use the data for this purpose. The name of the local authority, specific case information, and information about the progress of individual cases have all been redacted to avoid indirectly identifying cases.

\section{Methods}

The trackers and original case files allowed various linear and logistic regressions amongst other data analyses, using the following variables:

- weeks between LPM and issuing proceedings;

- weeks between LPM and stepping-down; 
- weeks between issuing proceedings and end of proceedings;

- outcome of care proceedings;

- date of referral for LPM;

- date case was stepped-down from pre-proceedings;

- outcome of pre-proceedings;

- date of issuing proceedings;

- date of ending proceedings;

- main reason for concern;

- child's age at time of LPM (or issuing if this is unavailable);

- child's gender;

- child's ethnicity;

- situation six months later;

- $\quad$ situation twelve months later.

The tight geographical scope of the study limits its applicability. Harwin et al. (2018) found huge regional variability, whereby courts in London were more likely to grant supervision orders, and less likely to grant care and placement orders, than courts in the North of England. One-quarter of London care proceedings cases ended with a care order, the lowest rate in the country. Their figures for 2016/2017 were as follows:

\begin{tabular}{lccccc}
\hline Region & \multicolumn{3}{l}{ Order } & & \\
\cline { 2 - 6 } & $\begin{array}{c}\text { SO } \\
\text { (per cent) }\end{array}$ & $\begin{array}{c}\text { CO } \\
\text { (per cent) }\end{array}$ & $\begin{array}{c}\text { PO } \\
\text { (per cent) }\end{array}$ & $\begin{array}{c}\text { SGO } \\
\text { (per cent) }\end{array}$ & $\begin{array}{c}\text { RO/CAO } \\
\text { (per cent) }\end{array}$ \\
\hline North West & 9 & 47 & 15 & 16 & 6 \\
Midlands & 13 & 40 & 20 & 12 & 9 \\
North East & 13 & 34 & 17 & 19 & 12 \\
South West & 14 & 33 & 17 & 16 & 10 \\
London & 25 & 28 & 10 & 19 & 10 \\
South East & 17 & 30 & 16 & 19 & 10 \\
This L.A. (for 2016/2017) & $42^{\mathrm{a}}$ & 26 & 12 & $18^{\mathrm{a}}$ & 8 \\
\hline
\end{tabular}

${ }^{a}$ Thirty-four per cent supervision orders with a parent; 8 per cent supervision orders under an SGO.

This local authority (in South East England) has an unusually high proportion of supervision orders granted: when using the whole period from 2013 to 2017, this falls to 30 per cent for supervision orders at home and 34 per cent for supervision orders overall, which is still a higher rate than for London more widely, and far higher than for other regions. The rate at which care orders are awarded is correspondingly lower than for London as a whole, and much lower than other areas. The profile otherwise resembles the rest of London in terms of SGOs, private law orders and placement orders. 


\section{Discussion}

\section{Overall trends}

Between 2013 and 2017, the average duration of both care proceedings and pre-proceedings became shorter and more likely to end with the child(ren) left at home.

Of the 937 children subject to LPMs that resulted in further action:

488 (52 per cent) went straight into proceedings, and 449 (48 per cent) were subject to pre-proceedings. Of the 449 pre-proceedings, 18 were 'interrupted' (e.g. the family moved to a different jurisdiction). Of the 431 with a clear outcome, 197 were stepped-down from pre-proceedings, and 234 were escalated to care proceedings.

The trend over time (excluding 2017 cases since some are still in progress or are excluded from the trackers) suggests more cases are stepping-down (see Figure 1a-also see how, in Figure 1b, the same trend emerges when cases are grouped by-family rather than by-child). The trend is even more apparent when expressing the proportion of preproceedings cases escalating into proceedings (see Figure $2 \mathrm{a}-$ given the similarities between Figure 1a and b, it is unsurprising that Figure 2b, grouped by-family rather than by-child, demonstrates a similar trend, since care proceedings are usually brought for each child in a family, even if the final orders are different). A binary logistic regression found the trend was statistically significant $(p<0.001)$ even when controlling for the demographics of the child and the type of case. The odds of a case stepping-down increased by an average of 37 per cent year-on-year, which cannot be accounted for by the composition of cases, and (taken in isolation) could represent either:

1. a higher threshold to issue proceedings;

2. a lower threshold to begin pre-proceedings;

3. a greater effectiveness at reducing the concerns in pre-proceedings cases so that they can be stepped-down, or

4. a greater willingness to step a case down rather than issue care proceedings.

In this respect, the findings seem inconsistent with wider research: Masson et al. (2013), in their comprehensive study of pre-proceedings cases in six local authorities, found no similar trend towards steppingdown rather than issuing, suggesting that organisation-level factors may have made the difference to the decisions in this local authority (Masson et al. also recognise considerable variation between local authorities in their study). However, while Masson's figure of 28 per cent of cases diverted from care is far lower than the overall figure in this study, it is very similar to the rate for cases in 2011 and 2012-the period which 

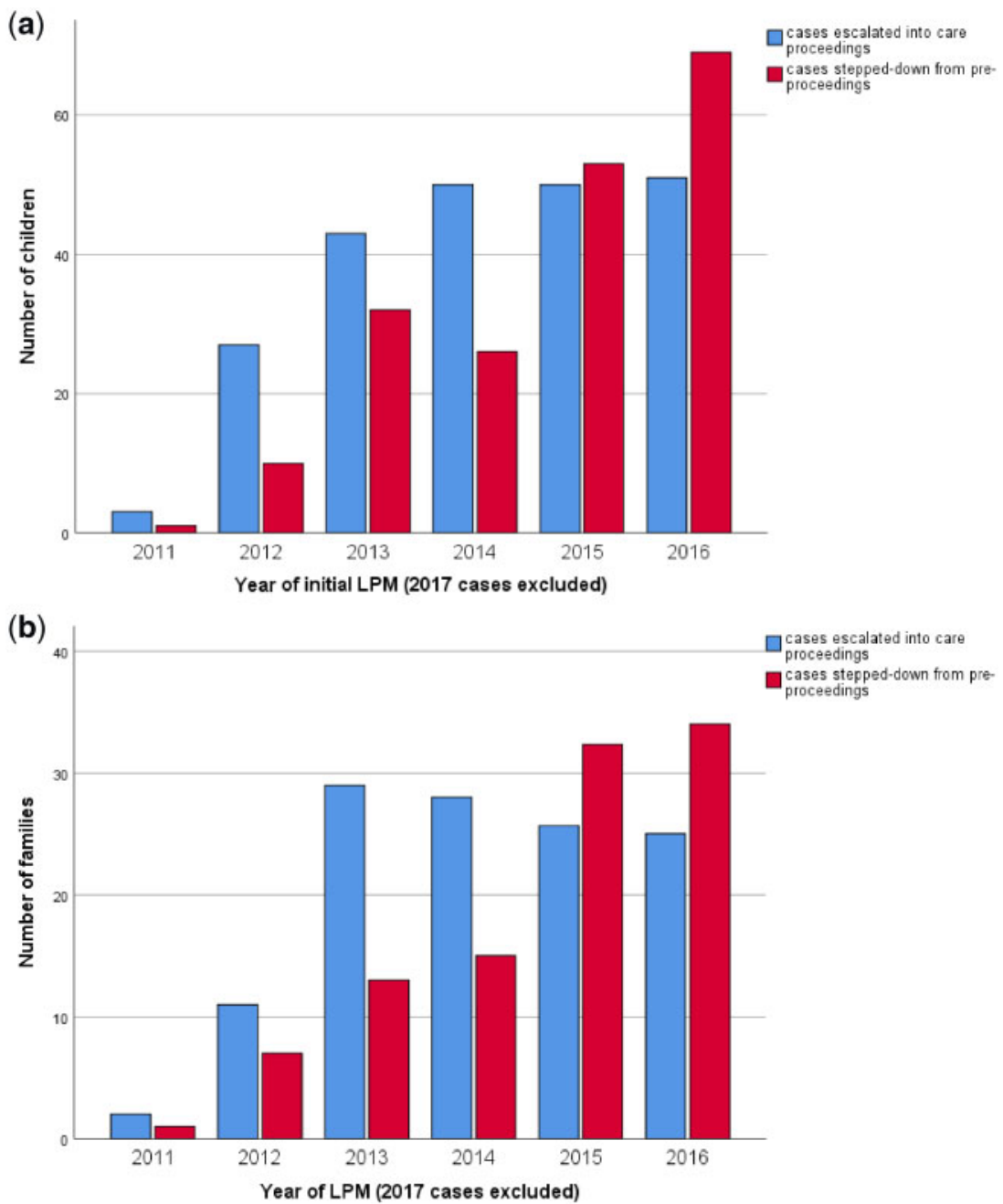

Figure 1: Frequency of cases stepped-down or escalated from pre-proceedings. (a) By year (by number of children). (b) By year (by number of families).

overlaps with their research, which was carried out from 2010 to 2012. This cannot be put down to the possibility that more recent cases (brought to pre-proceedings between 2013 and 2017) simply have not entered care proceedings yet: the same cut-off of a year after steppingdown applies to all cases in this sample. I cannot rule out that some of these cases were brought to court after a family moved to another local authority, but Masson et al. make this same caveat. Overall, the proportion of cases stepping-down in this local authority appears consistent with previous research as far as 2012, before increasing significantly. 

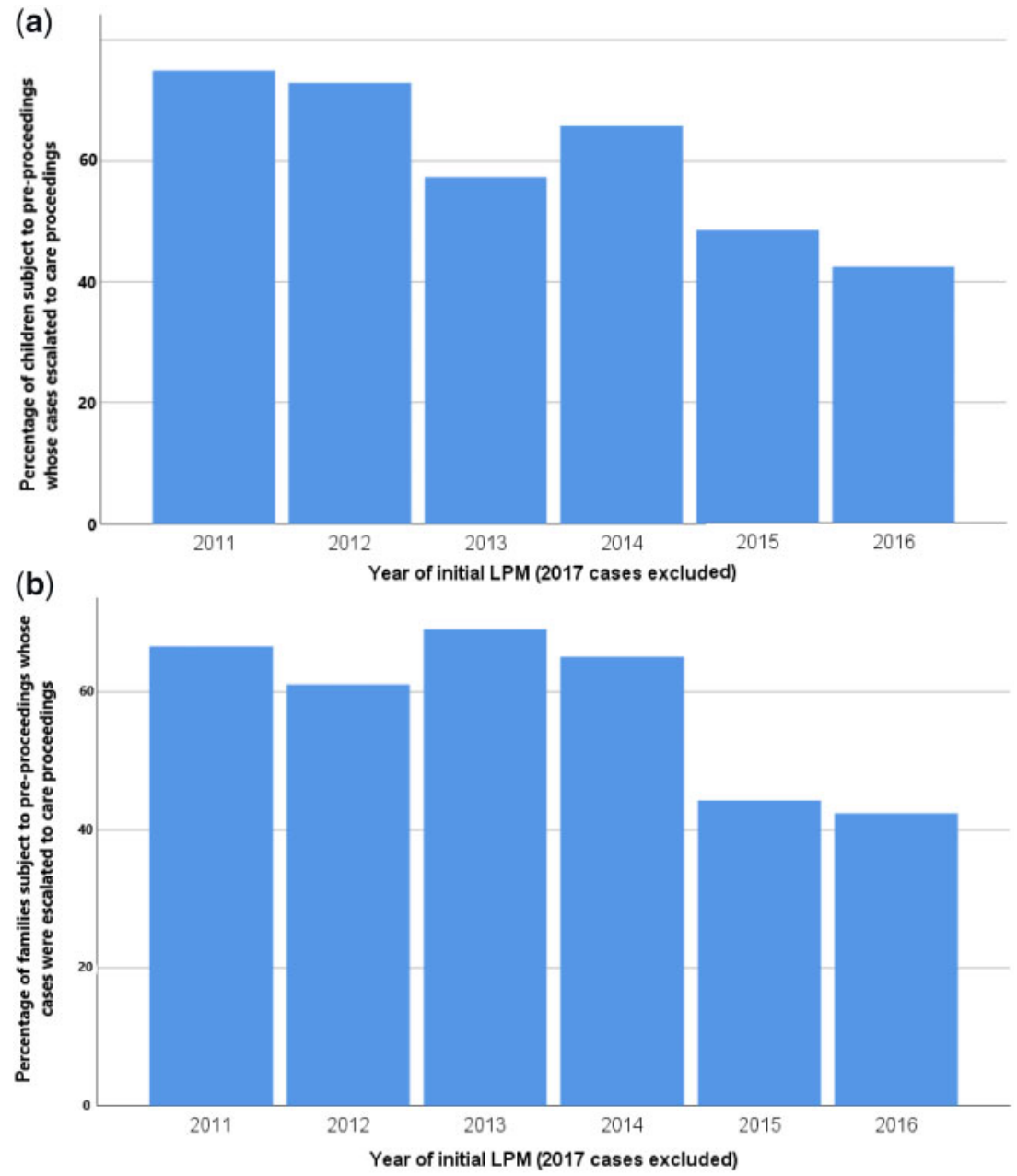

Figure 2: Proportion of pre-proceedings cases escalating into proceedings. (a) By year (by proportion of children). (b) By year (by proportion of families).

This coincided with a trend towards shorter periods of preproceedings before stepping-down (Figure 3). As Figure 3 shows, the length of pre-proceedings where the case ended up stepping-down decreased from nearly seventy weeks in 2012 to just over forty weeks in 2014-2016. This might support possibilities (3) and (4) above: a greater confidence in making decisions and a decreased tolerance for case 'drift', which could be due to a change in policy around case closure, reducing the number of pre-proceedings cases where the concerns had long abated but the case was kept open without effective work taking place. This trend is further supported by the pre-proceedings cases, which 


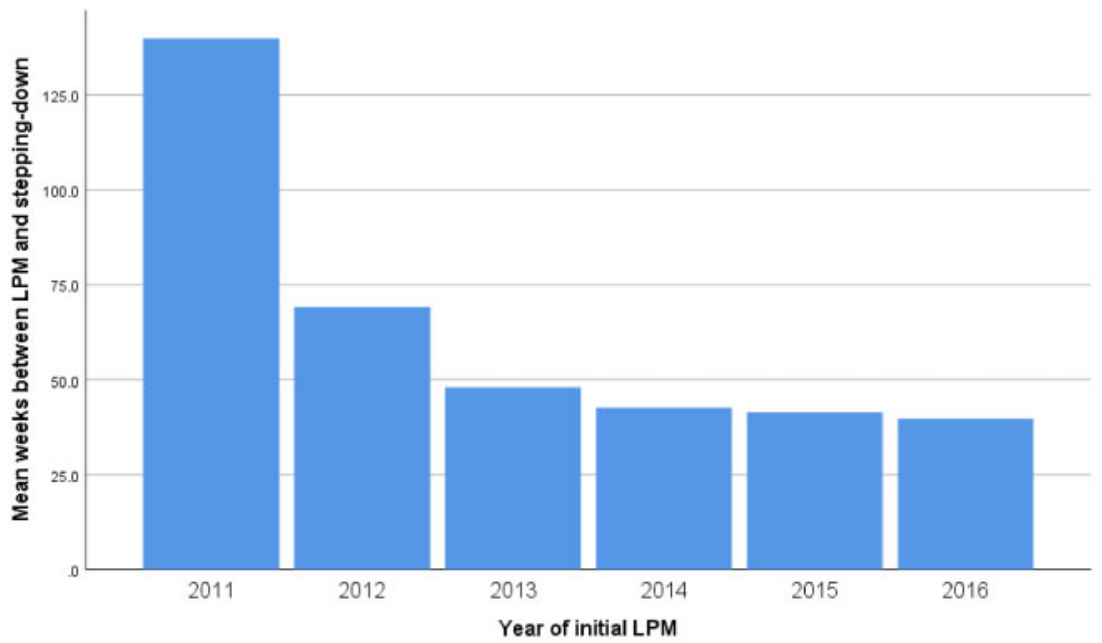

Figure 3: Average weeks from initial LPM (where the pre-proceedings process is initiated) to the final LPM (where the pre-proceedings process is ended with no further legal action).

eventually resulted in care proceedings (Figure 4). As Figure 4 shows, the local authority used to issue proceedings after, on average, twentythree weeks of pre-proceedings. By 2016, this flattened out at sixteen weeks. Again, this may reflect greater decisiveness in the preproceedings process. It also highlights a clear trend: the longer preproceedings continue, the more likely the case will be stepped-down rather than issued. Linear regressions testing factors behind the 'length' of pre-proceedings periods found that, other than the general trend that pre-proceedings have shortened, the length of pre-proceedings is unaffected by what kind of case it is, or the details of the child, with one possible exception.

\section{Physical abuse cases}

The data tentatively suggest that court cases regarding physical abuse (which disproportionately involve black children) are more likely to result in the child staying at home (when analysed by-child). In pre-proceedings cases, the same effect appears when analysing the sample by-child. In both cases, the effect disappears when analysing the sample by-family, which is more appropriate to the pre-proceedings sample where decisions usually apply to a whole family (while court orders are made by-child).

The logistic regression yielded this finding when using 'main reason for concern' as a control variable. No other category (sexual abuse, neglect, substance abuse, etc.) was statistically significant. 


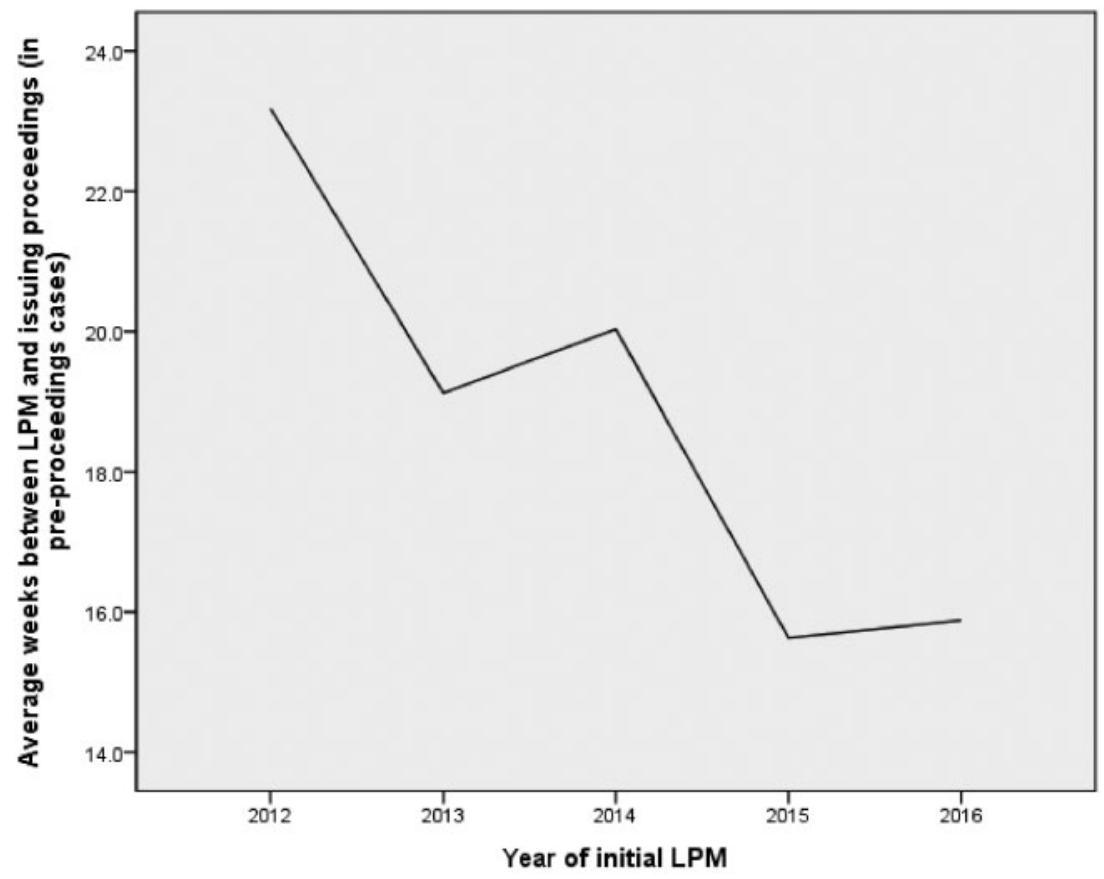

Figure 4: Average number of weeks from initial LPM (initiating pre-proceedings) to issuing care proceedings, by year.

The 'main reasons' in the dataset are also necessarily simplistic, and reflect the categories used in the tracker, where available-for earlier cases, it reflects the primary reasons given in the LPM minutes. Many cases involve more than one category, and therefore the 'main' reason is often arbitrary.

Where the reason for concern was physical abuse, the child was twice as likely (odds ratio: 2.25) to remain with parents at the end of a concluded proceedings. In court cases where the 'main concern' was physical abuse, 54 per cent of children (sixty out of 111) remained at home, compared to 37 per cent ( 221 out of 591) where the main concern was a different category. The link is no longer statistically significant when the dataset is reorganised by-family rather than by-child, so this finding is tentative, given that a few large families may be skewing the data.

Similarly, the odds of the case being stepped-down from preproceedings rather than escalated to care proceedings were $2.3 \times$ higher (across the 2011-2016 period). Including the available 2017 cases, the effect was still statistically significant $(p<0.05)$ and the odds of steppingdown were still over twice as high as for cases where the main reason for concern was something other than physical abuse. However, when 
the data are grouped by family, rather than by child, this link is no longer statistically significant.

At the court level, the analysis by-child is justified by the use of different orders for different children, so that finding is relevant. At preproceedings level, the analysis by-family (which produced no significant finding) is more pertinent, although it is still of interest that the same theme was present (in cases of physical abuse, and only in those cases) when the sample (which overlaps only partly with the court sample) was analysed by-child.

Analysis by demographics found that while Black African or Black Caribbean children made up 25.4 per cent of the overall dataset, they made up 43.2 per cent of physical abuse cases in pre-proceedings (nineteen children), and 43.9 per cent of physical abuse cases in care proceedings.

A logistic regression showed that Black African/Caribbean children are $2.7 \times$ as likely as other children in this dataset to have a 'main reason for concern' category of physical abuse. However, again this is a tentative finding: when the same test is carried out by family (rather than by child) there is still an over-representation of Black children in the sample, but this now falls below the level of statistical significance (changing the unit of analysis from the child to the family effectively halves the sample size, so the regression once more falls foul of limits-of-freedom).

But this still means that there are many cases going into court involving Black African/Caribbean children suffering physical abuse from their carers, and that these cases, having met the threshold for preproceedings or proceedings, are then more likely than other cases to subsequently fall below the threshold to issue, or below the threshold for removal (the court may find that a child is indeed at risk of significant harm, but not consider this harm sufficient to justify separating the child from their family at that stage).

This only gives a quantitative picture. The data could either mean:

1. The local authority may be quicker to start pre-proceedings or issue proceedings after a precipitating incident where a child is injured than they would be on other cases, and are more likely to do so when a child is Black. Masson et al. (2013) provide further context: they identified several cases with extensive social work involvement prior to a precipitating incident, where this incident (often a physical injury) was used as an 'opportunity to go into proceedings' (p. 92), where the caseholders had already considered the possibility of doing so. I would need to explore this sample in much more depth to be able to draw similar conclusions here.

2. The data may demonstrate that the local authority is successful at working with families in pre-proceedings and care proceedings 
when the issue is only one of getting them to stop using physical punishments.

3. Alternatively, none of these data can give us insight into what Mnookin and Kornhauser (1979) famously termed 'private ordering': the negotiations and deliberations that take place 'outside' of the court, with a view to presenting the court with as few contested points as possible. The lower likelihood of physical abuse cases resulting in escalation (from pre-proceedings) or separation (in care proceedings) may be less to do with the reduction of such abuse and more a reflection on the attitudes of the various agencies to instances of parents hitting their children: an outcome that favours the family may not indicate that the parents have stopped physically punishing their children, but that the relative harm of removal was deemed worse than the harm caused by physical chastisement.

4. Finally, the higher step-down rate may simply reflect factual findings: a suspicious injury to a child, if there is little or no previous involvement, can be something of an 'all-or-nothing' case depending on medical evidence-either a parent has deliberately injured them, or the child has sustained an injury innocently. In such cases, one would expect a decision in the family's favour as soon as the initial concern has been ruled out by medical evidence showing that the parents did not harm their child.

\section{'What happened next' for children stepped-down from pre- proceedings}

Overall, despite the increasing trend towards stepping-down pre-proceedings cases, there is no corresponding trend for cases to 'bounce back' and require further action.

After excluding outlier cases in 2011, 445 children have been subject to pre-proceedings in the sample. Of these, 214 (48.1 per cent) were stepped-down with no proceedings. Of the other 231 (51.9 per cent) that went into proceedings, 28 (6.3 per cent) ended with no public law order-twenty-three of these lived with a parent, three with family and two in care; fifty-one (11.5 per cent) ended with a supervision order and the child staying with a parent; seventy-three (16.4 per cent) ended with a care order and the child in care; twelve (2.7 per cent) ended with a care order and placement order and forty-nine (11 per cent) ended with a special guardianship order, of which thirteen also had a supervision order. This is broadly consistent with the nationwide figure of 20-25 per cent of SGOs having a supervision order (Masson et al., 2017). (This excludes proceedings that were interrupted, 2 care orders with the child at home, and 1 ward of court.) 
Six months after stepping-down from pre-proceedings:

- Sixty (30.6 per cent) of children were not involved with the local authority.

- Ninety-five (48.5 per cent) remained subject to a child in need plan.

- Thirty-two (16.3 per cent) remained subject to a child protection plan.

- Two were adults, and seven were 'remaining in care / adopted / SG' without their situation having changed.

Twelve months after stepping down:

- Eighty-five (63.4 per cent) were no longer involved with the local authority.

- Twenty-nine (21.6 per cent) were subject to child in need plans.

- Twelve (8.9 per cent) were subject to child protection plans.

- Three were adults, and five were 'remaining in care / adopted / SG' without their situation having changed.

This seems encouraging. Despite pre-proceedings becoming shorter over the past few years, and more likely to end in stepping-down, 'none' of the stepped-down cases had to return to LPMs within twelve months. Indeed, the majority had no further dealings with the local authority I should, however, note that:

1. this does not include cases that may still be open to a different local authority. From reading the file, some have obviously transferred. However, it would be impossible to know whether this applies to any other cases with no involvement in the Local Authority.

2. while their cases have not returned to court, a large minority of the stepped-down children remain subject to child protection or child in need plans, which is not the same as being closed, and indicates that the family's situation still requires statutory intervention, albeit outside of the court.

However, some cases which were stepped-down in pre-proceedings have been subject to further LPMs due to increased concerns: three children in two families were subject to another LPM, both eighteen months after previously being stepped-down. Given the small number and specific nature of the cases, details are omitted here due to the risk of pseudonymisation (the accidental breach of confidentiality by providing anonymous details of a person which nevertheless identify them). All three children ended up separated from their parents-two children in one family subject to a care order and one child in another family subject to a special guardianship order. 
These cases should be placed in a wider context: 214 children have been stepped-down from pre-proceedings; zero have returned to preproceedings or proceedings within twelve months, and three required care proceedings (a rate of about 1.4 per cent) within two years.

The proportion of stepped-down cases that ended up going to court is even lower than the proportion of court cases resulting in repeat proceedings after the child remained at home. The local authority issued care proceedings for 256 children that resulted in No Order or a Supervision Order. Of these 256, within twelve months, fourteen (5.4 per cent) had returned to care proceedings or (in one case) preproceedings. In ten cases (3.9 per cent), the child was in care. This compares to zero for stepped-down pre-proceedings cases. Overall, of the 256 children who remained at home after care proceedings, seventeen (6.6 per cent) now live in care, adopted or with a special guardian.

\section{Pre-proceedings cases that escalate into care proceedings}

This research also compared cases which involved pre-proceedings work prior to issuing proceedings, with 'immediate issue' cases that went straight to court after an LPM. These involve different kinds of cases: the most unambiguously problematic cases (e.g. where previous children have recently been removed, or where an emergency protection order is required because of a danger of imminent harm) would all be immediate-issue, while cases that do not require immediate protective action would go through pre-proceedings first. This suggests that the cases that go through pre-proceedings might be more challenging for decision makers: pre-proceedings cases include long-term, chronic but nonacute harm, where there may not be a clear-cut 'moment' at which the local authority needs to remove a child from their parents. For example, a case where a parent has inflicted horrifying injuries upon a child (triggering an application for an emergency protection order) might be easier to reach a decision on, compared to a case where a parent has been drinking heavily for many years and providing a substandard level of care to their children (which could be in pre-proceedings, barring a precipitating incident to take it into court).

A comparison of proceedings length over time shows shortening duration of proceedings, but is neutral as to the effect of pre-proceedings on duration of proceedings (Figure 5) - the graph clearly shows a clear downwards trend under the new PLO as the average length of proceedings has fallen from twelve months in 2012 to six months in 2016. The effect of a case having first been in pre-proceedings was much less pronounced. On average, cases that start with pre-proceedings spend slightly less time in proceedings than cases that issue immediately. 


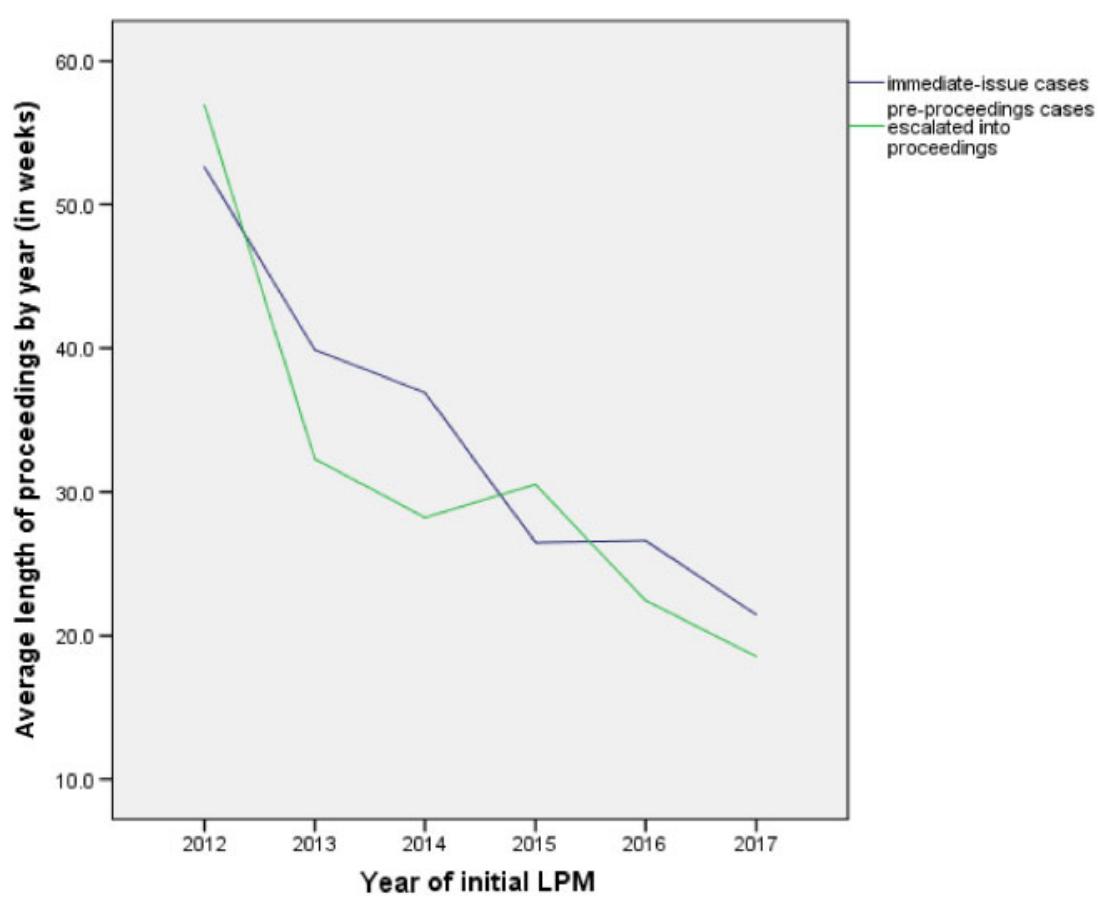

Figure 5: Average duration of care proceedings by year, showing both the cases which were subject to pre-proceedings, and cases which were subject to immediate-issue.

Linear regressions, after excluding the 2011 start cases (which seemed to be outliers and were unlikely to represent the majority of cases in that period), still show a statistically significant effect, albeit a very small one.

When comparing the characteristics of immediate-issue cases versus court cases that were originally in pre-proceedings, there were statistically significant differences for:

1. Age: a much higher proportion of the immediate-issue proceedings were infants. This is unsurprising and reflects the number of cases where the concerns were already high before birth or shortly afterwards-such cases would be less likely to go through preproceedings. The difference in children's ages is insignificant above this age (Figure 6).

2. Care Orders and Placement Orders (related to (1) above): this outcome was much more common in immediate-issue cases (18 per cent) than for cases that had gone through pre-proceedings first (5 per cent).

3. Care Orders with a child remaining in care: this outcome was more common when the case had originally gone through 


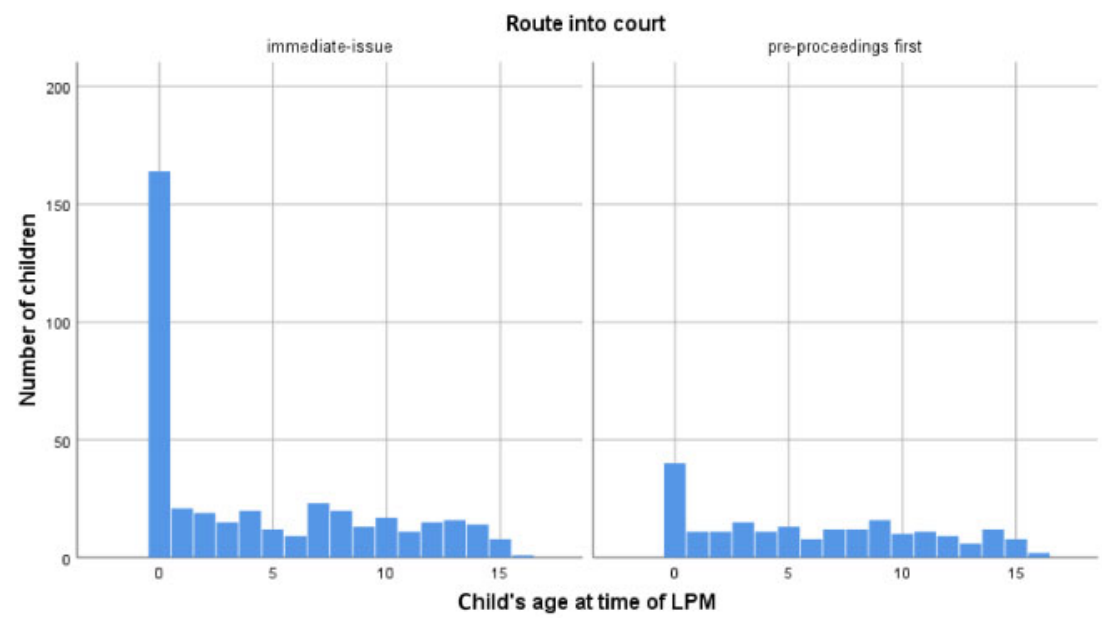

Figure 6: Age of children subject to care proceedings, comparing immediate-issue cases with those that have first gone through care proceedings.

pre-proceedings (32 per cent) than when a case had gone straight to court (22 per cent), perhaps because the possibility of the parents making changes has been more thoroughly explored in the former category. Again, this makes sense given the age profile of the two types of cases-an older child is more likely to remain in long-term foster care than to be adopted, relative to a younger child. Therefore, given that pre-proceedings cases are more likely to involve older children than immediate-issue cases, it is plausible that children who have gone through pre-proceedings before care proceedings are more likely to find themselves fostered than adopted. Indeed, this difference disappears after allowing for age as a control variable.

4. 'Main reason for concern': emotional abuse cases in court were more common amongst cases that had gone through preproceedings first (16 per cent compared to 6 per cent), while physical abuse cases (which are much more likely to end with the child at home) were more common amongst immediate-issue cases (18 per cent to 10 per cent). This makes sense given the chronic nature of emotional abuse (which may lend itself to pre-proceedings first) versus the acute and immediate nature of a non-accidental injury, for example.

\section{Summary of findings}

These findings refer to a single local authority in South East England: 
1. The proportion of pre-proceedings cases that are stepped-down, rather than escalated to proceedings, increased year-on-year. As recently as 2014, over 60 per cent of pre-proceedings cases resulted in proceedings, and for 2016 cases the figure was just over 40 per cent. A similar pattern occurred in care proceedings, where more cases are ending with the child at home.

2. During the same period, pre-proceedings have become shorter. Cases were in pre-proceedings for an average of forty weeks when they stepped down; cases that escalate to proceedings were issued within an average of sixteen weeks (down from twenty-three in 2012). Circumstantial evidence suggests a greater 'decisiveness' in the management of pre-proceedings cases.

3. Cases where the main concern is 'physical abuse' made up over one in six cases in the sample. When analysed by-child, physical abuse cases in care proceedings were significantly more likely to end with the child at home (under no order, or a supervision order) than cases with different main concern categories. The same effect appeared in pre-proceedings cases: physical abuse cases were over twice as likely to result in stepping-down (rather than entering proceedings) compared to other cases (although for these cases, the analysis by-family is more significant). Interestingly, 43 per cent of physical abuse cases involved Black children (compared to 25 per cent of the sample as a whole). A considerable subset of cases, involving physical abuse of Black children, were much more likely than other cases to be resolved to the local authority's or court's satisfaction. However, these are the most tentative findings in this study: unlike findings (1) and (2), these relationships were no longer statistically significant when grouping the sample by family, rather than by child (which effectively halves the sample size, so the numbers involved-already small-were too low for me to be confident in their significance).

4. Despite pre-proceedings cases increasing in number, decreasing in time and being increasingly likely to step-down, the 'follow-up' figures were encouraging (at least based on proxy indicators of statutory involvement). Even twelve months after stepping-down, none of the 214 cases had escalated back to another LPM, let alone proceedings. Of the latter, two families (involving three children) went into court, eighteen months after stepping-down, resulting in children living away from parents. This means that 0 per cent of stepped-down cases returned to LPM within twelve months and 1.4 per cent returned to court within the entire period. By (rough) comparison, amongst cases that are 'stepped-down' from a court (where the child remains with the parents under No Order or a Supervision Order), 5.4 per cent returned to court within twelve months and 6.6 per cent within the whole period. 
5. For the cases that progress into care proceedings, it is unclear whether the work done in pre-proceedings substantially improves the quality of work done in preparation for court-this question is more subjective and lacks a control group: pre-proceedings cases and immediate-issue cases have different characteristics. However, the data fit the national trend where the length of proceedings is falling year-on-year, for both categories of cases.

6. Cases that are escalated from pre-proceedings were less likely to involve infants, more likely to involve emotional abuse cases, less likely to involve physical abuse and more likely to end with children in care rather than adopted, compared with immediate-issue cases.

\section{Limitations of the study}

This study has inherent limitations: it refers to only one local authority in London, so does not allow for differences in policy and culture between different areas, or different outcomes across different regions. Even those findings that are statistically significant within this authority (by child and by family) do not necessarily apply nationwide or globally, although they do provide a case study for comparison. The quantitative nature of the study also means that individual case characteristics are unavoidably aggregated into broad categories that do not capture the variation between cases. Also, I should not confuse an output or proxy measure for an outcome: I cannot conclude that all those children who end up at home without further intervention are necessarily well caredfor (just as I cannot say whether every permanent placement outside the home has proved beneficial) - this would require a far deeper study. The six- and twelve-month follow-up points are arbitrary, although extending this point much further would prevent any analysis of more recent cases. Nevertheless, it means the study does not capture situations where a case has returned to court or pre-proceedings years after being steppeddown.

\section{Conclusions and implications for practice}

Notwithstanding these caveats, the research has identified some relevant implications for practice:

1. In this local authority, a shortening of both care proceedings and pre-proceedings (and a shift towards stepping-down pre-proceedings cases rather than escalating to court) was not associated with high levels of cases requiring further legal planning. Without 
becoming complacent, these findings suggest that seemingly successful resolutions of complex cases do not necessarily require over long periods of pre-proceedings or care proceedings work, nor an overly risk-averse approach to decision-making.

2. The tentative findings around physical abuse cases require a larger-scale quantitative study to test whether the 'by-child' findings (that physical abuse cases in court are less likely to result in separation from parents) hold true across a larger sample. If so, a qualitative study might be able to explore in more depth any mechanisms that account for these findings.

3. Such a study might also explore views and assumptions of service users about physical punishment, for cases where the child was injured by a parent exercising what they believed to be reasonable or at least lawful force, and consider the level at which physical abuse is best prevented.

4. Finally, the research model itself might provide a useful template for practitioners looking to carry out similar explorations of their own organisation's cases, and demonstrated the value of tracking data on pre-proceedings cases, without which the project would have been impossible. It provides an example of 'co-production' in practice, combining a university department's insights with the active involvement of the local authority in shaping and contributing to research, which is then more likely to be incorporated into dayto-day practice. This project led to the senior management team exploring the theme of physical abuse, ethnicity and culture in more depth, looking to engage service users and practitioners around the issue. The research also strengthened an existing partnership promoting research-mindedness in practice, informing in-house training strategies.

\section{Acknowledgements}

Thanks to Cate Pearton and Laura Vaz for their assistance with this project, and Stephen Kitchman and Briege Gilhooly for their permissions. Special thanks to Anna Fairtlough for her kind and invaluable assistance in preparing the article.

\section{Funding}

This project funded by the Academics in Practice programme, part of the South-East London Teaching Partnership.

Conflict of interest statement. None declared. 


\section{References}

Beckett, C., Dickens, J. and Bailey, S. (2016) Outcomes for Children of Shorter Court Decision-making Processes: A Follow-up Study of the Tri-borough Care Proceedings Pilot, CRCF.

Beckett, C. and Dickens, J. (2018) 'Making a target work: Messages from a pilot of the 6-month time limit on care proceedings in England', Child and Family Social Work, 23(3), pp. 390-8.

Broadhurst, K. and Holt, K. (2009) 'Partnership and the limits of procedure: Prospects for relationships between parents and professionals under the new Public Law Outline', Child and Family Social Work, 15(1), pp. 97-106.

DfE (2014) 'Court orders and pre-proceedings: For local authorities', April 2014, Department for Education.

Dickens, J. and Masson, J. (2016) 'The courts and child protection social work in England: Tail wags dog?', The British Journal of Social Work, 46(2), pp. 355-71.

Dustin, D. (2016) The McDonaldization of Social Work. London, Routledge.

Gupta, A. and Lloyd-Jones, E. (2016) 'Re B-S: A glass half full? An exploration of the implications of the Re $B-S$ judgment on practice in the family courts', Child \& Family Social Work, 21(4), pp. 539-47.

Harwin, J., Alrouh, B., Bedston, S. and Broadhurst, K. (2018) Care Demand and Regional Variability in England: 2010/11 to 2016/17, Centre for Child and Justice Research.

Holt, K. and Kelly, N. (2015) 'Exploring the personal narratives of social workers engaged in pre-proceedings child care practice: An English case study' 5th European Conference for Social Work Research: Re-visioning Social Work with Individuals, Collectives and Communities: Social Work Research, 22-24 April 2015, Ljubljana.

Lord Chief Justice (2017) 'The Lord Chief Justice's Report', Presented to Parliament Pursuant to Section 5(1) of the Constitutional Reform Act 2005, The Judiciary of England and Wales. https://assets.publishing.service.gov.uk/government/uploads/ system/uploads/attachment_data/file/306282/Statutory_guidance_on_court_orders_ and_pre-proceedings.pdf (accessed October 14, 2019).

Masson, J. M., Dickens, J., Bader, K. and Young, J. (2013) Partnership By Law? The Pre-proceedings Process for Families on the Edge of Care Proceedings, available online at: https://papers.ssrn.com/sol3/papers.cfm?abstract_id=2281146.

Masson, J. (2014) 'The quality of care proceedings reform', Journal of Social Welfare and Family Law, 36(1), pp. 82-84.

Masson, J., Dickens, J., Bader, K., Garside, L. and Young, J. (2017) How Is the PLO Working? What Is Its Impact on Court Process and Outcome?: The Outcomes of Care Proceedings for Children Before and After Care Proceedings Reform Study Interim Report, UEA.

Masson, J., Dickens, J., Bader, K., Garside, L. and Young, J. (2018) 'Summary reports, Reforming Care Proceedings', UEA, available online at: http://www.uea. ac.uk/centre-research-child-family/research-briefs (accessed August 24, 2018).

Mnookin, R. and Kornhauser, L. (1979) 'Bargaining in the shadow of the law: The case of divorce', The Yale Law Journal, 88(5), pp. 950-97.

Munro, E. (2004) 'The Impact of Audit on Social Work Practice', The British Journal of Social Work, 34(8), pp. 1075-95. 
Peckover, S., White, S. and Hall, C. (2007) 'Making and managing electronic children: E-assessment in child welfare', Information, Community and Society, 11(3), 375-94.

Platt, D. and Turney, D. (2013) 'Making threshold decisions in child protection', The British Journal of Social Work 2014, 44, 1472-90.

Rutter, D. and Fisher, M. (2013) Knowledge Transfer in Social Care and Social Work: Where Is the Problem?, Canterbury, Personal Social Services Research Unit. 